\title{
Effects of Intercropping with Tolerant Plants on Cadmium Accumulation of Brassica chinensis
}

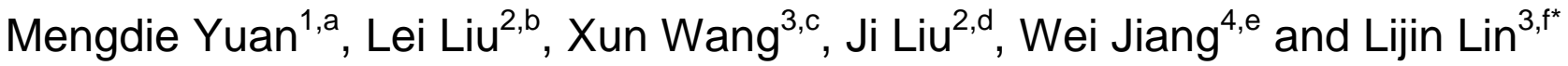 \\ ${ }^{1}$ College of Horticulture, Sichuan Agricultural University, Chengdu, Sichuan, China \\ ${ }^{2}$ Chengdu Academy of Agriculture and Forestry Sciences, Chengdu, Sichuan, China \\ ${ }^{3}$ Institute of Pomology and Olericulture, Sichuan Agricultural University, Chengdu, Sichuan, China \\ ${ }^{4}$ College of Chemistry and Life Science, Chengdu Normal University, Chengdu, Sichuan, China \\ a1376114883@qq.com, 'skyskyskylover@163.com.cn, ${ }^{\text {c3 } 35744023 @ q q . c o m, ~}{ }^{\text {d3 } 34905418 @ q q . c o m, ~}$ \\ '1399945180@qq.com, 'ilj800924@163.com
}

${ }^{*}$ Corresponding author. Mengdie Yang, Lei Liu and Xun Wang contributed equally to this work.

Keywords: Brassica chinensis; lolerant plant; Cadmium; Intercropping

Abstract: The pot experiment was conducted to study the effects of intercropping with cadmium $(\mathrm{Cd})$ tolerant plants (Arenaria serpyllifolia, Clinopodium confine, Ranunculus sieboldii and Plantago asiatica) on growth and $\mathrm{Cd}$ accumulation of Brassica chinensis. Compared with the monoculture, only intercropping with $C$. confine increased the root biomass, shoot biomass, and photosynthetic pigment contents of $B$. chinensis, and intercropping with $A$. serpyllifolia, $R$. sieboldii and $P$. asiatica decreased that. Intercropping with tolerant plants increased the Cd contents in roots and shoots of $B$. chinensis, and the orders of that were ranked as intercropping with $C$. confine $>$ intercropping with $P$. asiatica $>$ intercropping with $A$. serpyllifolia $>$ intercropping with $R$. sieboldii $>$ monoculture. Intercropping with $C$. confine increased the $\mathrm{Cd}$ contents in roots and shoots of $B$. chinensis by $107.67 \%$ and $72.00 \%$ respectively compared with the monoculture Therefore, intercropping with Cd tolerant plants could increase the $\mathrm{Cd}$ uptake of $B$. chinensis, which should be carefully considered in Cd-contaminated soil.

\section{Introduction}

With the increase of the heavy metals pollution in soil, China's cadmium $(\mathrm{Cd})$ contaminated arable land area reache $1.3 \times 10^{4}$ ha, involving 11 provinces and cities 25 areas [1]. In addition, the $\mathrm{Cd}$ content in vegetable is also exceeded, about $24.1 \%$ of the vegetable samples exceeded in China [2]. Therefore, for arable land or garden of heavy metal pollution control is imminent. The adjustment of planting pattern is a relatively new remediation method for remedying the soil heavy metal by agricultural ecology. It can reduce the heavy metal contents in agricultural products and improve the edible safety of vegetables, including low-enrichment plant rotation, different enrichment ability of vegetable intercropping, hupeyaccumulator plants intercropping with crop, etc. [3]. When the vegetables intercropping with hupeyaccumulator plants, the toxic effects of heavy metals on vegetables may be able to reduce, and reduces the heavy metal enrichment of vegetables [4]. Some studies show that intercropping with hyperaccumulator plant Sedum alfredii significantly reduces the $\mathrm{Cd}$ and zinc contents in maize and ryegrass [5]. In terms of vegetables, the absorption capacity of $\mathrm{Cd}$ in different vegetables is related to the type of vegetables, and the absorption capacity of leaf vegetables is usually greater than that of fruit vegetables [6].

Brassica chinensis is a cruciferous vegetable with adaptability, fast growth and high yield [7]. In this study, the seedlings of $B$. chinensis were intercropped with the Cd tolerant plants Arenaria serpyllifolia, Clinopodium confine, Ranunculus sieboldii and Plantago asiatica [8] under $\mathrm{Cd}$-contaminated soil. The aim of the study was to determine whichtolerant plant could reduce the $\mathrm{Cd}$ accumulated in B. chinensis seedlings, and to provide a reference for phytoremediation of soils contaminated with heavy metals. 


\section{Materials and Methods}

Materials. In April 2015, the seedlings of A. serpyllifolia, C. confine, R. sieboldii and $P$. asiatica with two or three euphyllas expanded were collected from the Ya'an campus farm of the Sichuan Agricultural University $\left(29^{\circ} 59^{\prime} \mathrm{N}, 102^{\circ} 59^{\prime} \mathrm{E}\right)$, China, from uncontaminated soil areas. The seeds of $B$. chinensis were purchased in the market.

The inceptisol soil samples (purple soil in the Genetic Soil Classification of China) were collected from the Ya'an campus farm in August 2013. The basic properties of the soil are described in Lin et al. (2014) [9].

Experimental Design. The experiment was conducted in the greenhouse of the Ya'an campus farm from February to June 2015. The soil samples were air dried and passed through a 5-mm sieve. Three kilograms of the air-dried soil was weighed into each polyethylene pot $(18 \mathrm{~cm}$ high and $21 \mathrm{~cm}$ in diameter). $\mathrm{Cd}$ was added to soils as $\mathrm{CdCl}_{2} \cdot 2.5 \mathrm{H}_{2} \mathrm{O}$ at $10 \mathrm{mg} / \mathrm{kg}$ [10] in February 2015. The soil moisture was maintained at $80 \%$ of field capacity for 2 months. The seeds of $B$. chinensis were sown in farmland of the Ya'an campus farm in March 2015. The five experimental treatments in the experiment were $B$. chinensis monoculture (control), and $B$. chinensis intercropping with each of the four plant species (A. serpyllifolia, $C$. confine, $R$. sieboldii and $P$. asiatica). The uniform seedlings of B. chinensis (two euphyllas expanded) were transplanted into each pot in April 2015. The monoculture planted four seedlings of $B$. chinensis in each pot, and the intercropping treatment planted three seedlings of $B$. chinensis and one tolerant plant seedling in each pot. Each treatment was replicated five times using a completely randomized design with $10-\mathrm{cm}$ spacing between pots, and the soil moisture content was maintained at $80 \%$ of field capacity from the time the plants were transplanted into the pots until the time the plants were harvested. 2 months later (June 2015), the upper mature leaves of $B$. chinensis were collected to determine the photosynthetic pigment (chlorophyll $a$, chlorophyll $b$, total chlorophyll, and carotenoid) contents [11]. The plants were then gently removed from the soil, and the roots, stems, and leaves were washed with deionized water and dried at $80^{\circ} \mathrm{C}$ to constant weight for dry weight and Cd content determination [12].

Statistical analyses. Statistical analyses were conducted using SPSS 13.0 statistical software (IBM, Chicago, IL, USA). Data were analyzed by one-way analysis of variance with least significant difference (LSD) at the $\mathrm{p}=0.05$ confidence level. The following calculated were used: translocation factor $(\mathrm{TF})=\mathrm{Cd}$ content in shoots/ Cd content in roots [13].

\section{Results and Discussion}

Biomass. Under Cd stress, intercropping with $C$. confine increased the root, stem and leaf and shoot biomasses of $B$. chinensis compared with the monoculture, but intercropping with A. serpyllifolia, $R$. sieboldii and $P$. asiatica decreased that (Table 1). The biomass of $B$. chinensis was ranked as: intercropping with $C$. confine $>$ monoculture $>$ intercropping with $P$. asiatica $>$ intercropping with $A$. serpyllifolia $>$ intercropping with $R$. sieboldii. Compared with the monoculture, intercropping with $C$. confine increased the root, stem and leaf and shoot biomasses of B. chinensis by $2.73 \%(p>0.05)$, $7.20 \%(p<0.05), 16.92 \%(p<0.05)$ and $13.92 \%(p<0.05)$, respectively. Intercropping with $R$. sieboldii and $P$. asiatica improved the root/ shoot ratio of $B$. chinensis, but intercropping with $A$. serpyllifolia and $C$. confine had no obvious effect or reduced that (Table 1).

Photosynthetic Pigment Content. Like the biomass, only intercropping with $C$. confine increased the chlorophyll $a$, chlorophyll $b$, total chlorophyll and carotenoid contents in $B$. chinensis compared with the monoculture, which increased by $8.96 \%(p<0.05), 19.26 \%(p<0.05), 10.66 \%(p<0.05)$ and $17.52 \%(p<0.05)$, respectively (Table 2). Intercropping with A. serpyllifolia, $R$. sieboldii and $P$. asiatica decreased the chlorophyll $a$, chlorophyll $b$, total chlorophyll and carotenoid contents in $B$. chinensis compared with the monoculture. Intercropping with $R$. sieboldii and $P$. asiatica improved the chlorophyll $\mathrm{a} / \mathrm{b}$ of $B$. chinensis, and intercropping with $A$. serpyllifolia and $C$. confine reduced that (Table 2). The order of chlorophyll a/b was intercropping with $P$. asiatica $>$ intercropping with $R$. 
sieboldii $>$ monoculture $>$ intercropping with A. serpyllifolia $>$ intercropping with $C$. confine.

Table 1 Biomass of Brassica chinensis

\begin{tabular}{lccccc}
\hline \multicolumn{1}{c}{ Treatments } & $\begin{array}{c}\text { Roots } \\
\text { (g/plant) }\end{array}$ & $\begin{array}{c}\text { Stems } \\
\text { (g/plant) }\end{array}$ & $\begin{array}{c}\text { leaves } \\
\text { (g/plant) }\end{array}$ & $\begin{array}{c}\text { Shoots } \\
\text { (g/plant) }\end{array}$ & $\begin{array}{c}\text { Root/ shoot } \\
\text { ratio }\end{array}$ \\
\hline Monoculture & $0.293 \pm 0.003 \mathrm{a}$ & $0.542 \pm 0.008 \mathrm{~b}$ & $1.218 \pm 0.010 \mathrm{~b}$ & $1.760 \pm 0.018 \mathrm{~b}$ & 0.166 \\
A. serpyllifolia & $0.266 \pm 0.006 \mathrm{~b}$ & $0.468 \pm 0.006 \mathrm{~d}$ & $1.138 \pm 0.013 \mathrm{c}$ & $1.606 \pm 0.018 \mathrm{~d}$ & 0.166 \\
C. confine & $0.301 \pm 0.013 \mathrm{a}$ & $0.581 \pm 0.013 \mathrm{a}$ & $1.424 \pm 0.011 \mathrm{a}$ & $2.005 \pm 0.024 \mathrm{a}$ & 0.150 \\
R. sieboldii & $0.261 \pm 0.010 \mathrm{~b}$ & $0.432 \pm 0.007 \mathrm{e}$ & $1.064 \pm 0.020 \mathrm{~d}$ & $1.496 \pm 0.027 \mathrm{e}$ & 0.174 \\
$P$. asiatica & $0.291 \pm 0.006 \mathrm{a}$ & $0.493 \pm 0.010 \mathrm{c}$ & $1.184 \pm 0.010 \mathrm{~b}$ & $1.677 \pm 0.024 \mathrm{c}$ & 0.174 \\
\hline
\end{tabular}

Table 2 Photosynthetic pigment content in Brassica chinensis

\begin{tabular}{lccccc}
\hline \multicolumn{1}{c}{ Treatments } & $\begin{array}{c}\text { Chlorophyll } a \\
(\mathrm{mg} / \mathrm{g})\end{array}$ & $\begin{array}{c}\text { Chlorophyll } b \\
(\mathrm{mg} / \mathrm{g})\end{array}$ & $\begin{array}{c}\text { Total chlorophyll } \\
(\mathrm{mg} / \mathrm{g})\end{array}$ & $\begin{array}{c}\text { Chlorophyll } \\
\mathrm{a} / \mathrm{b}\end{array}$ & $\begin{array}{c}\text { Carotenoid } \\
(\mathrm{mg} / \mathrm{g})\end{array}$ \\
\hline Monoculture & $0.681 \pm 0.009 \mathrm{~b}$ & $0.135 \pm 0.006 \mathrm{~b}$ & $0.816 \pm 0.003 \mathrm{~b}$ & 5.044 & $0.234 \pm 0.002 \mathrm{~b}$ \\
A. serpyllifolia & $0.492 \pm 0.007 \mathrm{~d}$ & $0.099 \pm 0.008 \mathrm{c}$ & $0.591 \pm 0.015 \mathrm{~d}$ & 4.970 & $0.172 \pm 0.005 \mathrm{~d}$ \\
C. confine & $0.742 \pm 0.010 \mathrm{a}$ & $0.161 \pm 0.009 \mathrm{a}$ & $0.903 \pm 0.002 \mathrm{a}$ & 4.633 & $0.275 \pm 0.004 \mathrm{a}$ \\
R. sieboldii & $0.462 \pm 0.010 \mathrm{e}$ & $0.091 \pm 0.005 \mathrm{c}$ & $0.553 \pm 0.015 \mathrm{e}$ & 5.087 & $0.161 \pm 0.003 \mathrm{e}$ \\
P. asiatica & $0.619 \pm 0.006 \mathrm{c}$ & $0.121 \pm 0.010 \mathrm{~b}$ & $0.740 \pm 0.004 \mathrm{c}$ & 5.156 & $0.220 \pm 0.002 \mathrm{c}$ \\
\hline
\end{tabular}

Cadmium Content. Intercropping with tolerant plants increased the $\mathrm{Cd}$ contents in roots, stems, leaves and shoots of $B$. chinensis compared with the monoculture (Table 3 ). The Cd contents in roots, stems, leaves and shoots of $B$. chinensis were ranked as intercropping with $C$. confine $>$ intercropping with $P$. asiatica $>$ intercropping with $A$. serpyllifolia $>$ intercropping with $R$. sieboldii $>$ monoculture. Intercropping with $A$. serpyllifolia increased the Cd contents in roots and shoots of $B$. chinensis by $66.87 \%(p<0.05)$ and $54.22 \%(p<0.05)$ respectively compared with the monoculture, intercropping with $C$. confine increased by $107.67 \%(p<0.05)$ and $72.00 \%(p<0.05)$ respectively compared with the monoculture, intercropping with $R$. sieboldii increased by $41.71 \%(p<0.05)$ and $34.67 \%(p<0.05)$ respectively compared with the monoculture, and intercropping with $P$. asiatica increased by $84.05 \%$ $(p<0.05)$ and $60.00 \%(p<0.05)$ respectively compared with the monoculture. Intercropping with tolerant plants reduced the TF of $B$. chinensis, and the order of TF was monoculture $>$ intercropping with $R$. sieboldii $>$ intercropping with $A$. serpyllifolia $>$ intercropping with $P$. asiatica $>$ intercropping with $C$. confine. (Table 3 ).

Table 3 Cadmium content in Brassica chinensis

\begin{tabular}{lccccc}
\hline \multicolumn{1}{c}{ Treatments } & $\begin{array}{c}\text { Roots } \\
(\mathrm{mg} / \mathrm{kg})\end{array}$ & $\begin{array}{c}\text { Stems } \\
(\mathrm{mg} / \mathrm{kg})\end{array}$ & $\begin{array}{c}\text { Leaves } \\
(\mathrm{mg} / \mathrm{kg})\end{array}$ & $\begin{array}{c}\text { Shoots } \\
(\mathrm{mg} / \mathrm{kg})\end{array}$ & TF \\
\hline Monoculture & $3.26 \pm 0.113 \mathrm{e}$ & $0.29 \pm 0.010 \mathrm{e}$ & $3.12 \pm 0.057 \mathrm{~d}$ & $2.25 \pm 0.042 \mathrm{~d}$ & 0.690 \\
A. serpyllifolia & $5.44 \pm 0.127 \mathrm{c}$ & $0.39 \pm 0.016 \mathrm{c}$ & $4.73 \pm 0.184 \mathrm{~b}$ & $3.47 \pm 0.134 \mathrm{~b}$ & 0.638 \\
C. confine & $6.77 \pm 0.297 \mathrm{a}$ & $0.53 \pm 0.013 \mathrm{a}$ & $5.23 \pm 0.170 \mathrm{a}$ & $3.87 \pm 0.141 \mathrm{a}$ & 0.572 \\
R. sieboldii & $4.61 \pm 0.099 \mathrm{~d}$ & $0.33 \pm 0.007 \mathrm{~d}$ & $4.12 \pm 0.099 \mathrm{c}$ & $3.03 \pm 0.071 \mathrm{c}$ & 0.657 \\
$P$. a siatica & $6.00 \pm 0.156 \mathrm{~b}$ & $0.43 \pm 0.014 \mathrm{~b}$ & $4.92 \pm 0.156 \mathrm{ab}$ & $3.60 \pm 0.127 \mathrm{ab}$ & 0.600 \\
\hline
\end{tabular}

\section{Conclusions}

Under Cd stress, only intercropping with $C$. confine increased the root biomass, shoot biomass, and photosynthetic pigment contents of $B$. chinensis compared with the monoculture, and intercropping with $A$. serpyllifolia, $R$. sieboldii and $P$. asiatica decreased that. Intercropping with tolerant plants 
increased the $\mathrm{Cd}$ contents in roots and shoots of $B$. chinensis, and the orders of that were ranked as intercropping with $C$. confine $>$ intercropping with $P$. asiatica $>$ intercropping with $A$. serpyllifolia $>$ intercropping with $R$. sieboldii $>$ monoculture. Therefore, intercropping with tolerant plants could increase the $\mathrm{Cd}$ uptake of $B$. chinensis, which should be carefully considered in Cd-contaminated soil.

\section{Acknowledgements}

This work was financially supported by the Application Infrastructure Project of Science and Technology Department of Sichuan Province (2016JY0258).

\section{References}

[1] C.Y. Ma, D.J. Cai and H. Yan: Henan Chemical and Industry Vol. 30, (2013), p. 17.

[2] X.B. Zeng, L.F. Li and X.R. Mei: Scientia Agricultura Sinica, Vol. 40, (2007), p. 2507.

[3] X.J. Guo: Difference in Vegetable Yield and Cadmium Accumulation with Six Different Planting Patterns in Cadmium Soil (Huazhong Agricultural University, 2012).

[4] Z. Zhang, K.X. Lu and Q.F. Meng: Journal of Ningbo University (NSEE) Vol. 23, (2010), p. 23.

[5] C.A. Jiang, Q.T. Wu, S.H. Wu and X.X. Long: China Environmental Science Vol. 29, (2009), p. 985.

[6] X.H. Ouyang, Y.J. Zhao, F.Z. Liu, Y. Li, R.G. Shi and Y.J. Li: Journal of Agro-Environment Science Vol. 27, (2007), p. 67.

[7] Y. Chen, T.Q. Li, X.E. Yang and Y.F. Jin: Chinese Journal of Applied Ecology Vol. 20, (2009), p. 736.

[8] L.J. Lin, Q. Jin, Y.J. Liu, B. Ning, M.A. Liao and L. Luo: Environmental Toxicology and Chemistry Vol. 33, (2014), p. 2422.

[9] L. Lin, D. Yang, F. Tang, L. Luo, M. Liao and L.Yuan: Chinese Journal of Soil Science Vol. 46, (2015), p. 483.

[10]L. Lin, M. Liao, Y. Ren, L. Luo, X. Zhang, D. Yang and J. He: PLoS ONE Vol. 9, (2014), p. e114957.

[11]Z.B. Hao, J. Chang and Z. Xu: Plant Physiology Experiment (Harbin Institute of Technology Press, China 2004).

[12]S.D. Bao: Agrochemical Soil Analysis (3rd edition, China Agriculture Press, Beijing, China 2000).

[13]F. Rastmanesh, F. Moore and B. Keshavarzi: Bulletin of Environmental Contamination and Toxicology Vol. 85, (2010), p. 515. 